\title{
INVENTARISASI KARAGAMAN JENIS FLORA MANGROVE DI PULAU MECAN KOTA BATAM
}

\section{THE INVENTORY OF MANGROVE DIVERSITY AT MECAN ISLAND BATAM}

\author{
RAMSES \\ Prodi Pendidikan Biologi Universitas Riau Kepulauan \\ ramses.firdaus@gmail.com
}

\begin{abstract}
Abstak
Setiap ekosistem mangrove mempunyai keanekaragaman vegetasi yang berbeda, begitu juga halnya pada kawasan mangrove di Pulau Mecan. Pengumpulan data vegetasi dilakukan dengan pencacahan jenisjenis flora mangrove di sepanjang garis transek. Metode Spot Check dilakukan untuk melengkapi informasi flora mangrove diluar jalur garis transek, dilakukan dengan cara mengamati dan memeriksa zona-zona tertentu dalam ekosistem mangrove yang memiliki ciri khusus. Pengukuran parameter fisik-kimia air menunjukan bahwa salinitas $\left(29-30^{\circ} \%\right)$, pH $(6,0-6,5)$, suhu $\left(29-30^{\circ} \mathrm{C}\right)$, DO $(6,5 \mathrm{mg} / \mathrm{l})$, kecerahan $(8 \mathrm{~m})$. Hasil inventarisasi flora pada lokasi pengamatan menunjukkan bahwa terdapat 32 jenis flora penyusun hutan mangrove yang teramati. Jenis flora mangrove tersebut terdiri dari 15 jenis mangrove sejati, 3 jenis mangrove pendukung, dan 14 jenis asosiasi mangrove. Inventarisasi terhadap jenis flora mangrove sejati meliputi Rhizophora. mucronata, R. apiculata, Bruguiera gymnorrhiz, B. cylindrica, Lumnitzera littorea, L. recemos, Ceriops tagal, C. decandra, Avicennia lanata, A. alba, Xylocarpus granatum, X. mollucensis dan Nypa fruticans. Mangrove sejati didominan oleh Rizophora mucronata dan R. apiculata. Sedangkan jenis mangrove pendukung terdiri Aegiceras corniculatum, Scyphiphora hydrophyllaceae dan Excoecaria agallocha. Pada kawasan pengamatan juga dijumpai jenis mangrove asosiasi atau ikutan yaitu Acanthus ilicifolius, Terminalia catappa, Hibiscus tiliaceus, Pemphis acidula, Ximenia americana, Dischidia bengalensis, Dischidia rafflesiana, Sarcolobus banksii, Sesuvium portulacastrum, Acrostichum aureum, Acrosticum aureum, Scaevola taccada, Pandanus tectorius dan Clerodendrum inerme.
\end{abstract}

Kata kunci: Flora, mangrove, inventarisasi, Pulau Mecan, keragaman jenis.

\begin{abstract}
Each mangrove location has different vegetation diversity, as well as mangroves at Mecan island. The data collection of vegetation was done by enumerating the types of mangrove along the transect line. Spot Check method was done to complete the mangrove information from outside the transect line, it was done by observing and checking certain zones at mangrove ecosystem which had special characteristics. Water physical-chemical parameter measurements showed that salinity (29-30\%), pH (6.0-6.5), temperature (29$\left.30^{\circ} \mathrm{C}\right)$, DO $(6.5 \mathrm{mg} / \mathrm{l})$, brightness $(8 \mathrm{~m})$. The flora inventory results at the observation location showed that 32 observed species forested mangrove. This mangrove type consisted of 15 species of true mangrove, 3 types of supporting mangrove, and 14 types of associate mangrove. True mangrove Inventory included Rhizophora. mucronata, R. apiculata, Bruguiera gymnorrhiz, B. cylindrica, Lumnitzera littorea, L. recemos, Ceriops tagal, C. decandra, Avicennia lanata, A. alba, Xylocarpus granatum, X. mollucensis and Nypa fruticans. True Mangrove was dominated by Rizophora mucronata and R. apiculata. Meanwhile supporting mangrove type consisted Aegiceras corniculatum, Scyphiphora hydrophyllaceae and Excoecaria agallocha. At the observation areas were also found associate mangrove species that was Acanthus ilicifolius, Terminalia catappa, Hibiscus tiliaceus, Pemphis acidula, Ximenia americana, Dischidia bengalensis, Dischidia rafflesiana, Sarcolobus banksii, Sesuvium portulacastrum, Acrostichum aureum, Acrosticum aureum, Scaevola taccada, Pandanus tectorius and Clerodendrum inerme.
\end{abstract}

Keywords: Flora, mangrove, inventory, Mecan Island, Diversity. 


\section{PENDAHULUAN}

Ekosistem mangrove merupakan ekoton (daerah peralihan) yang unik, yang menghubungkan kehidupan biota daratan dan laut. Fungsi ekologis ekosistem mangrove sangat khas dan kedudukannya tidak terganti oleh ekosistem lainnya. Hutan mangrove yang merupakan ekosistem peralihan antara darat dan laut, sudah sejak lama diketahui mempunyai fungsi ganda dan merupakan mata rantai yang sangat penting dalam memelihara keseimbangan siklus biologi di suatu perairan.

Stuktur komunitas mangrove merefleksikan kondisi ekologi mangrove di suatu kawasan. Faktor oseanografi memberi kantribusi terhadap hal ini. Lamanya pasang berpengaruh besar terhadap perubahan salinitas pada ekosistem mangrove secara linier dimana pada saat pasang salinitas tinggi dan berkurang pada saat air surut. Lamanya air pasang juga berpengaruh pada distribusi spesies, struktur vegetasi dan fungsi ekosistem. Ekosistem mangrove yang digenagi air hampir setiap saat hanya akan ditumbuhi oleh Ryzophora mucronata, sedangkan Bruguera sp dan Xylocarpus sp jarang mendominasi pada daerah yang selalu tergenang air (Aksornkoae, 1993 dalam Bahar, 2004).

Vegetasi mangrove mempunyai morfologi dan anatomi tertentu sebagai respons fisiogenetik terhadap habitatnya. Vegetasi mangrove yang bersifat halopitik menyukai tanah-tanah yang bergaram, misalnya Avicennia sp., Bruguiera sp., Lumnitzera sp., Rhizophora sp., dan Xylocarpus sp. Vegetasi tersebut menentukan ciri lahan mangrove berdasarkan sebaran, dan sangat terikat pada habitat mangrove. Vegetasi yang tidak terikat dengan habitat mangrove antara lain adalah Acanthus sp., Baringtonia sp., Callophyllum sp., Calotropis sp., Cerbera sp., Clerodendron sp., Derris sp., Finlaysonia sp., Hibiscus sp., Ipomoea sp., Pandanus sp., Pongamia sp., Scaevola sp., Sesuvium sp., Spinifex sp., Stachytarpheta sp., Terminalia catappa, Thespesia sp., dan Vitex sp. (Gunarto, 2004).

Sebagai daerah peralihan antara laut dan daratan, hutan mangrove mempunyai gradien sifat lingkungan yang sangat ekstrim. Pasang-surut air laut menyebabkan terjadinya perubahan beberapa faktor lingkungan yang besar, terutama suhu dan salinitas. Oleh karena itu, hanya beberapa jenis tumbuhan yang memiliki daya toleransi yang tinggi terhadap lingkungan yang ekstrim tersebut saja yang mampu bertahan hidup dan berkembang didalamnya. Kondisi yang terjadi tersebut juga menyebabkan rendahnya keanekaragaman jenis, namun disisi lain kepadatan populasi masing-masing jenis umumnya tinggi (Pramudji, 2001). 
Tiap lokasi mangrove mempunyai keanekaragaman vegetasi yang berbeda, begitu juga halnya pada kawasan mangrove di Pulau Mecan. Penelitian ini bertujuan untuk menginventarisasi ragan jenis flora mangrove pada daerah pengamatan.

\section{METODE PENELITIAN}

\section{Waktu dan Tempat}

Penelitian ini dilakuakan pada bulan Juni 2015 di kawasan hutan mangrove Pulau Mecan, Kelurahan Sekanak Raya, Kecamatan Belakang Padang Kota Batam.

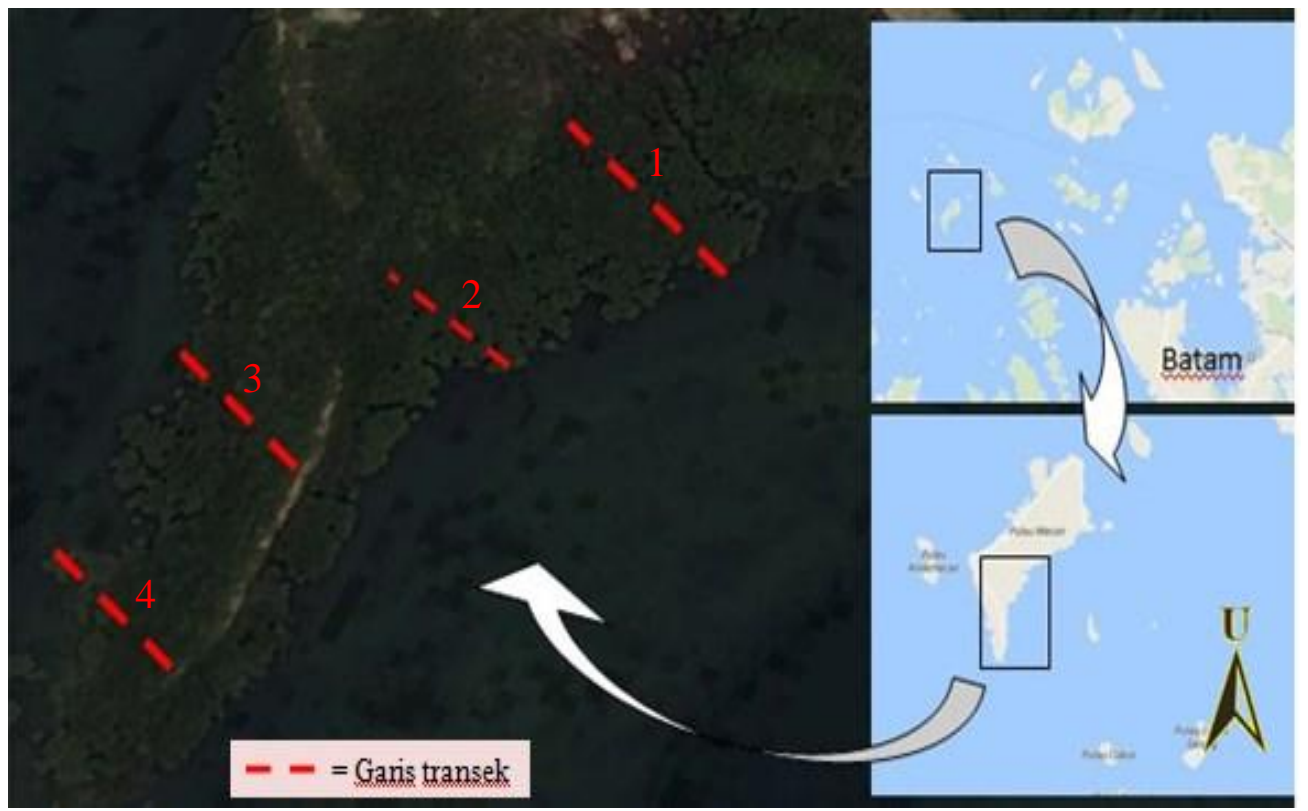

Gambar 1. Peta Lokasi Penelitian

\section{Alat dan Bahan}

Alat-alat yang digunakan terdiri dari alat pengukuran parapeter ait laut berupa termometer air raksa, refraktometer, $\mathrm{pH}$, pingan sechi, GPS, kamera, kantung plastik, label beserta alat-alat tulis, dan data sheet.

\section{Teknik Pengumpulan Data}

Sebelum melakukan pengumpulan data, dilakukan pengamatan lapangan yang meliputi keseluruhan kawasan hutan mangrove dengan tujuan untuk melihat secara umum keadaan fisiognomi dan komposisi tegakan hutan serta keadaan pasang surut daerah setempat dan lain sebagainya. Selanjutnya dilakukan pembagian daerah pengamatan menjadi empat titik yang mewakili daerah yang masih memiliki vegetasi mangrove tebal, vegetasi sedang dan stasiun yang mewakili daerah yang hanya sedikit ditumbuhi vegetasi 
mangrove serta pada kawasan yang terdapat bekas aktifikat penebangan. Pada masingmasing stasiun ini dibuat garis transek tegak lurus dengan garis pantai ke arah darat sebagai panduan jelajah dengan mengunakan alat bantu GPS. Panjang garis transek bervariasi menurut ketebalan vegetasi mangrove yang menjadi penghubung terestial dan perairan.

Pengumpulan data flora manrove dilakukan dengan pencacahan jenis-jenis flora mangrove di sepanjang garis transek. Kemudian metode Spot Check dilakukan untuk melengkapi informasi jenis flora lainnya yang tidak teramati pada jalur garis transek. Metode Spot Check dilakukan dengan cara mengamati dan memeriksa zona-zona tertentu dalam ekosistem mangrove yang memiliki ciri khusus.

\section{Identifikasi Flora Mangrove}

Identifikasi flora mangrove di lakukan dengan pengamatan secara langsung di lapangan di empat titik pengamatan. Pengamatan dilakukan baik di zona terluar, pertengahan dan zona peralihan dengan vegetasi daratan. Identifikasi flora manrove dilakukan dengan memperhatikan perbedaaan akar, daun, bunga dan buah mangrove (Welly, et al., 2010) serta menampakan fisiologi tegakan mangrove. Identifikasi mangrove merujuk pada Pedoman Teknis Pengenalan dan Pengelolaan Ekosistem Mangrove (Bengen, 2004), Panduan Pengenalan Mangrove di Indonesia (Noor et, al., 2006) dan Mangrove Guidebook For Southeast Asia (Giesen, et al., 2006).

\section{HASIL DAN PEMBAHASAN}

Hasil pengukuran parameter fisik-kimia air menunjukan bahwa salinitas (29$30 \%$ oо $)$ pH $(6,0-6,5)$, suhu $\left(29-30^{\circ} \mathrm{C}\right)$, DO $(6,5 \mathrm{mg} / \mathrm{l})$, kecerahan $(8 \mathrm{~m})$. Parameter lingkungan perairan ini sudah sesuai dengan baku mutu.

Tabel 1. Parameter fisika dan kimia perairan pada lokasi penelitian

\begin{tabular}{llcc}
\hline Parameter & Alat ukur & Satuan & Nilai \\
\hline Salinitas & Repraktometer & $\mathrm{ppm}$ & $28-29$ \\
Suhu & Termometer & ${ }^{\circ} \mathrm{C}$ & $29-30$ \\
PH & PH Meter & & $6,0-6,5$ \\
DO & Do Meter & $\mathrm{mg} / 1$ & 6,5 \\
Kecerahan & Pingan sechi & $\mathrm{m}$ & 8 \\
\hline
\end{tabular}


Berdasarkan hasil pengamatan Pulau Mecan memiliki topografi datar dan landai dengan kemiringan kelandaian berkisar 20-30\%. Kawasan yang di tumbuhi vegetasi mangrove berapa pada bagian timur dan selatan pulau, sedangkan pada bagian utara dan barat pulau hampir tidak ditemukan vegetasi mangrove. Pada bagian timur dan selatan merupakan kawasan yang terlindungi oleh gelombang sehingga memungkinkan terdapatnya endapan lumpur dan berpasir. Secara oseonografi pasang surut pada kawasan terdapat 2 (dua) kali pasang dan 2 (dua) surut dalam waktu 24 jam dengan ketingian dan lama waktu pasang surut berfluktuasi sepanjang tahun.

\section{Requested time: 2015-06-04 Thu 12:00 AM SGT}

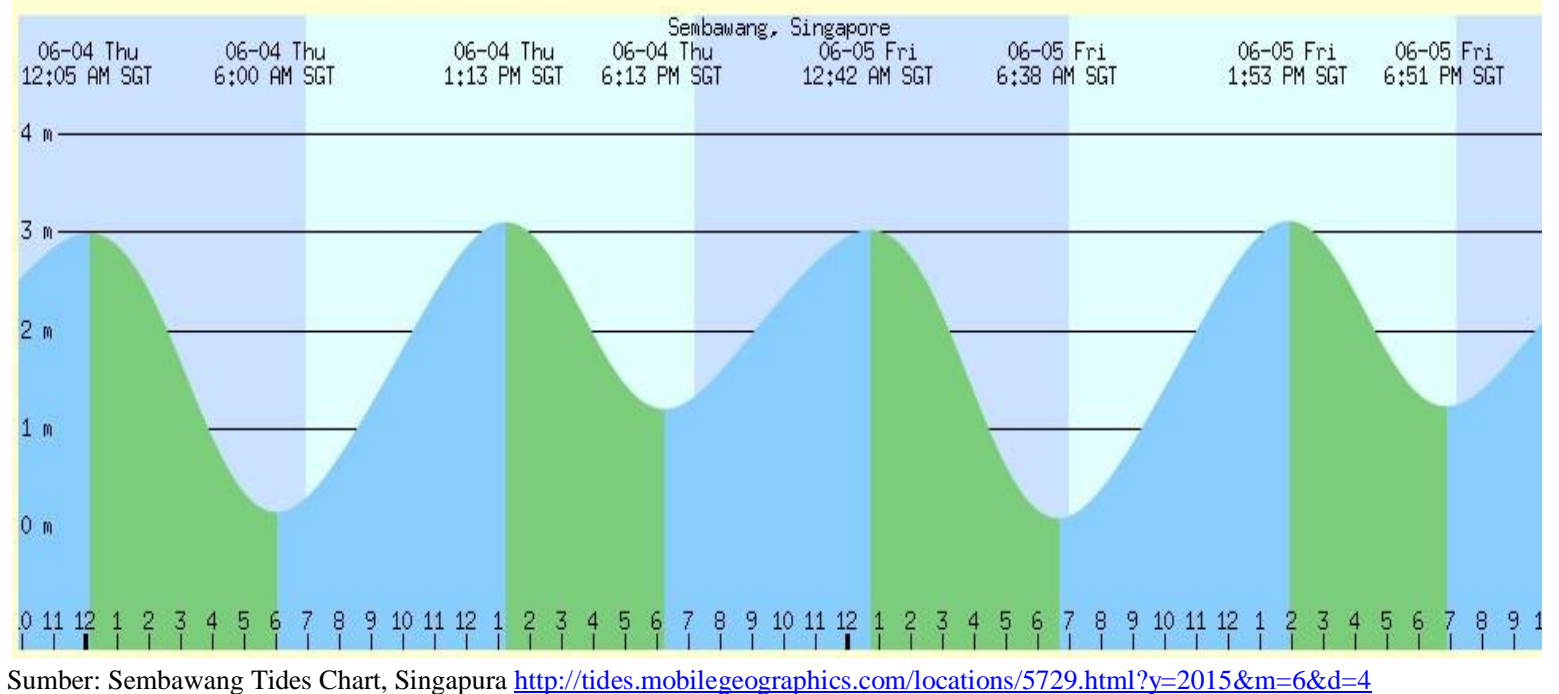

Gambar: Profil Pasang Surut Harian pada Lokasi Pengamatan (Tanggal 4 Juni 2015)

Karakterisrik geografi, pola pasang surut dan nilai parameter fisika-kima lingkungan perairan yang berlaku pada kawasan ini sangat memungkinkan terjadinya penyebaran vegetasi mangrove dengan keragaman yang tinggi. Prosses terjadinya pasang surut dalam lingkungan mangrove sangat penting dalam hal mensuplai oksigen dan respisasi meskipun hal ini masih dipengaruhi oleh elevasi, ketajamn lereng topografi dan karakteristik subtran khususnya tekstur tanah (Hutchings, et al., 2001 dalam Bahar, 2004). Pertumbuhan mangrove jenis Rhizophoraceae (B. gymnorrhiza, B.sexangula, C. tagal, $R$. apiculata, R.mucronata, dan R.stylosa, ) terutama pada tahapan propagul menjadi semai (seedling) sangat dipengaruhi oleh beberapa faktor seperti; salinitas, temperatur perairan, arus pasut, tinggi pasut, jenis substrat, ombak/gelombang pasang, kekeruhan air, intensistas penyinaran matahari, kelandaian lokasi, dan sebagainya (Lasibani dan Kamal, 
2010). Salinitas memiliki peran yang sangat dominan dalam pertumbuhan tanaman mangrove (Poedjiraharjoe, 2007; Aksornkoae, 1993 dalam Bahar, 2004).

Menurut Kitamura et al. (1997) dalam Gunarto (2004), vegetasi mangrove dapat dibagi menjadi tiga, yaitu vegetasi utama (sejati), vegetasi pendukung, dan vegetasi asosiasinya. Hasil inventarisasi flora mangrove di Pulau Mecan di jumpai sebanyak 32 jenis flora penyusun hutan mangrove yang teramati. Jenis flora mangrove tersebut terdiri dari 15 jenis mangrove sejati, 3 jenis mangrove pendukung, dan 14 jenis asosiasi mangrove. Inventarisasi terhadap jenis flora mangrove di lokasi pengamatan secara lengkap disajikan pada Table 2 .

Tabel 2. Ragam jenis flora mangrove pada masing-masing lokasi pengamatan

\begin{tabular}{|c|c|c|c|c|c|c|}
\hline \multirow{2}{*}{ Family } & \multirow{2}{*}{ Spesies } & \multicolumn{4}{|c|}{ Stasiun Pengamatan } & \multirow{2}{*}{ Nama Lokal } \\
\hline & & 1 & 2 & 3 & 4 & \\
\hline \multicolumn{7}{|c|}{ Mangrove Utama (Sejati) } \\
\hline \multirow[t]{8}{*}{ Rhizophoraceae } & Rhizophora mucronata & $v$ & $v$ & $v$ & $v$ & Bakau hitam \\
\hline & Rhizophora apiculata & $v$ & $v$ & $v$ & $v$ & Bakau \\
\hline & Bruguiera gymnorrhiza * & - & $v$ & $v$ & - & Tumu, Tanjang \\
\hline & Bruguiera cylindrica* & - & - & - & - & Tanjang putih \\
\hline & Lumnitzera littorea & - & $v$ & $v$ & - & Cingam \\
\hline & Lumnitzera recemos & - & $v$ & & $v$ & Sesup \\
\hline & Ceriops tagal* & - & - & - & - & Tengah \\
\hline & Ceriops decandra & - & $v$ & $v$ & - & Cabe-cabe \\
\hline \multirow[t]{2}{*}{ Avicenniaceae } & Avicennia lanata & $v$ & & $v$ & - & Api-api \\
\hline & Avicennia alba* & - & - & - & - & Api-api \\
\hline \multirow[t]{2}{*}{ Sonneratiae } & Sonneratia caseolaris* & - & - & - & - & Pedada \\
\hline & Sonneratia Alba & $v$ & & $v$ & - & Perpat \\
\hline \multirow[t]{2}{*}{ Meliaceae } & Xylocarpus granatum & $v$ & $v$ & & $v$ & Nyirih \\
\hline & Xylocarpus mollucensis * & - & - & - & - & Nyirih batu \\
\hline$\frac{\text { Arecaceae }}{\text { Nypoideae }}$ & Nypa fruticans * & - & - & - & - & Nipah \\
\hline \multicolumn{7}{|c|}{ Mangrove Pendukung } \\
\hline \multirow[t]{2}{*}{ Myrsinaceae } & Aegiceras corniculatum & - & $v$ & $v$ & - & $\begin{array}{l}\text { Teruntum, } \\
\text { kacang-kacang }\end{array}$ \\
\hline & Scyphiphora hydrophyllaceae* & - & - & - & - & $?$ \\
\hline Euphorbiaceae & Excoecaria agallocha $*$ & - & - & - & - & Buta-buta \\
\hline \multicolumn{7}{|c|}{ Flora Asosiasi (ikutan) } \\
\hline Acanthaceae & Acanthus ilicifolius* & - & - & - & - & Jeruju \\
\hline Combretaceae & Terminalia catappa* & - & - & - & - & Ketapang \\
\hline Malvaceae & Hibiscus tiliaceus* & - & - & - & - & Waru \\
\hline Lythraceae & Pemphis acidula* & - & - & - & - & Sentigi \\
\hline Ximeniaceae & $\begin{array}{l}\text { Ximenia americanal } \\
\text { Ziziphus littorea* }\end{array}$ & - & - & - & - & Bidara \\
\hline \multirow[t]{2}{*}{$\begin{array}{l}\text { Apocynaceae/ } \\
\text { Asclepiadaceae }\end{array}$} & Dischidia bengalensis* & - & - & - & - & Daun korpa \\
\hline & Dischidia rafflesiana* & - & - & - & - & Akar bani \\
\hline Apocynaceae & Sarcolobus banksii* & - & - & - & - & $?$ \\
\hline
\end{tabular}




\begin{tabular}{lllllll} 
Aizoaceae & Sesuvium portulacastrum* & - & - & - & - & Gelang laut \\
Pteridaceae & Acrostichum aureum* $^{*}$ & - & - & - & - & Piyai \\
\hline Goodeniaceae & Scaevola taccada* & - & - & - & - & Bakung-bakung \\
Pandanaceae & Pandanus tectorius $^{*}$ & - & - & - & - & $\begin{array}{l}\text { Pandan Laut } \\
\text { Keranji, Kayu } \\
\text { Lamiaceae }\end{array}$ \\
\hline
\end{tabular}

Keterangan: $\quad v=$ dijumpai di sekitar garis transek $*=$ dijumpai diluar garis transek

Inventarisasi terhadap jenis flora mangrove sejati meliputi Rhizophora. mucronata, R. apiculata, Bruguiera gymnorrhiz, B. cylindrica, Lumnitzera littorea, L. recemos, Ceriops tagal, C. decandra, Avicennia lanata, A. alba, Xylocarpus granatum, X. mollucensis dan Nypa fruticans. Mangrove sejati didominan oleh Rizophora mucronata dan R. apiculata.

Sedangkan jenis mangrove pendukung terdiri Aegiceras corniculatum, Scyphiphora hydrophyllaceae dan Excoecaria agallocha. Pada kawasan pengamatan juga dijumpai jenis mangrove asosiasi atau ikutan yaitu Acanthus ilicifolius, Terminalia catappa, Hibiscus tiliaceus, Pemphis acidula, Ximenia americana, Dischidia bengalensis, Dischidia rafflesiana, Sarcolobus banksii, Sesuvium portulacastrum, Acrostichum aureum, Acrosticum aureum, Scaevola taccada, Pandanus tectorius dan Clerodendrum inerme.

Flora mangrove di Pulau Mecan secara umum memiliki kesamaan jenis dan karakter pola zona pertumbuhan dengan yang telah dilaporkan Gunarto, (2004), bahwa pada perairan dengan salinitas tinggi di tepi pantai dijumpai komunitas Rhizophora apiculata, R. mucronata, Soneratia alba, dan Bruguera gymnorrhiza. Pada perairan dengan salinitas yang lebih rendah di tepi sungai dijumpai Nypa fruticans, R. apiculata, dan Lumnitzera littorea sebagai vegetasi utama, serta Heritiera littoralis, Excoecaria agallocha, Aegiceras corniculatum, Acrostichum aureum, dan Hibiscus tileaceus sebagai vegetasi pendukung dan asosiasinya. $R$. apiculata dan $R$. mucronata merupakan vegetasi mangrove yang mempunyai kerapatan tinggi.

\section{KESIMPULAN}

Pengukuran parameter fisik-kimia air di perairan Pulau Mecan menunjukan bahwa salinitas $\left(29-30^{\circ} \%\right), \mathrm{pH}(6,0-6,5)$, suhu $\left(29-30^{\circ} \mathrm{C}\right), \mathrm{DO}(6,5 \mathrm{mg} / \mathrm{l})$, kecerahan $(8 \mathrm{~m})$. Hasil inventarisasi flora pada lokasi pengamatan menunjukkan bahwa terdapat 32 jenis flora penyusun hutan mangrove yang teramati. Jenis flora mangrove tersebut terdiri dari 15 jenis 
mangrove sejati, 3 jenis mangrove pendukung, dan 14 jenis asosiasi mangrove. Inventarisasi terhadap jenis flora mangrove sejati meliputi Rhizophora. mucronata, $R$. apiculata, Bruguiera gymnorrhiz, B. cylindrica, Lumnitzera littorea, L. recemos, Ceriops tagal, C. decandra, Avicennia lanata, A. alba, Xylocarpus granatum, X. mollucensis dan Nypa fruticans. Mangrove sejati didominan oleh Rizophora mucronata dan R. apiculata. Sedangkan jenis mangrove pendukung terdiri Aegiceras corniculatum, Scyphiphora hydrophyllaceae dan Excoecaria agallocha. Pada kawasan pengamatan juga dijumpai jenis mangrove asosiasi atau ikutan yaitu Acanthus ilicifolius, Terminalia catappa, Hibiscus tiliaceus, Pemphis acidula, Ximenia americana, Dischidia bengalensis, Dischidia rafflesiana, Sarcolobus banksii, Sesuvium portulacastrum, Acrostichum aureum, Acrosticum aureum, Scaevola taccada, Pandanus tectorius dan Clerodendrum inerme.

\section{REFERENSI}

Bahar, A. 2004. Kajian Kesesuaian dan Daya Dukung Ekosistim Mangrove untuk Pengembangan Ekowisata Digugus Pulau Tanakeke, Kabupaten Takalar Sulawesi Selatan. Thesis. Sekolah Pascasarjana Institut Pertanian Bogor. Bogor.

Bengen, D. G. 2004. Pedoman Teknis: Pengenalan dan Pengelolaan Ekosistem Mangrove. PKSPL-IPB. Bogor.

Giesen, W., Wulffraat, S., Zieren, M and Scholten L., 2006. Mangrove Guidebook For Southeast Asia. FAO and Wetlands International, Dharmasarn Co., Ltd., Bangkok, Thailand. 186 pp.

Gunarto, 2004. Konservasi Mangrove sebagai Pendukung Sumber Hayati Perikanan Pantai. Jurnal litbang Pertanian, Volume 23 (1): 15-21.

Noor, Y. R., Khazali, M., dan Suryadiputra, I N.N. 2006. Panduan Pengenalan Mangrove di Indonesia. Wetlands dan Dirjen PHKA, Bogor.

Onrizal dan Kusmana, C., 2008. Studi Ekologi Hutan Mangrove di Pantai Timur Sumatera Utara. Biodiversitas, Volume 9 (1): 25-29.

Poedjiraharjoe, E., 2007. Dendogram Zonasi Pertumbuhan Mangrove Berdasarkan Habitatnya di Kawasan Rehabilitasi Pantai Utara Jawah Tengah Bagian Barat. Jurnal Ilmu Kelautan. Vol. 1 (2) 10-21. 
Pramudji, 2001. Ekosistem Hutan Mangrove dan Peranannya Sebagai Habitat Berbagai Fauna Aquatik. Oseana, Volume XXVI (4):13 - 23

Welly, M., Sanjaya, W., Sumerta, I N., dan Anom D. N., 2010. Identifikasi Flora dan Fauna Mangrove Nusa Lembongan dan Nusa Ceningan. Coral Triangle Center dan Balai Pengelolaan Hutan Mangrove Wilayah I, Bali.

Lasibani, S. M. dan Kamal, E., 2010. Pola Penyebaran Pertumbuhan Propagul Mangrove Rhizophoraceae Di Kawasan Pesisir Sumatera Barat. Jurnal Mangrove dan Pesisir X (1): 33-38 